\title{
Useful biomarkers for assessing the adverse health effects of PCBs in allergic children: pediatric molecular epidemiology
}

\author{
Mayumi Tsuji
}

Received: 18 September 2014/ Accepted: 30 September 2014/Published online: 26 October 2014

(C) The Japanese Society for Hygiene 2014

\begin{abstract}
The incidences of childhood allergies have been increasing in recent years in many parts of the world. The development of allergic disorders is attributed to a complex series of interactions between individuals' genetic backgrounds and their immune and psychoneurotic responses to environmental factors. Among the various possible environmental causes of childhood allergies, the early exposure of developing infants to air pollutants and the presence of persistent chemical pollutants such as pesticides have been suggested most frequently. Therefore, it is very important to obtain epidemiological evidence of direct associations between clearly defined adverse health effects and exposure to low levels of pollutants. However, there are no useful biomarkers for assessing such associations. Thus, we planned to establish reliable health-related biomarkers that could be used to investigate these relationships in children. The serum concentrations of several sub-types of polychlorinated biphenyl (PCB) congeners were found to be significantly correlated with interleukin (IL)-8 mRNA expression among asthmatic children. In addition, IL-22 mRNA expression was found to be particularly useful for detecting the effects of environmental pollutants, especially PCB congeners, in a sub-population of vulnerable children who exhibited positive immunoglobulin E (IgE) responses to milk or egg. Furthermore, we detected significant differences in IL-22 mRNA expression between the IgE-negative non-asthmatic subjects and the asthmatic children who exhibited positive IgE reactions toward egg or milk. In conclusion, IL-8 and IL22 mRNA expressions could be useful biomarkers for
\end{abstract}

M. Tsuji ( $\square)$

Department of Environmental Health, University of Occupational and Environmental Health, 1-1 Iseigaoka, Yahatanishi-ku, Kitakyusyu 807-8555, Japan

e-mail: tsuji@med.uoeh-u.ac.jp detecting sub-populations of children who are particularly vulnerable to the adverse health effects of environmental pollutants, especially PCBs.

Keywords Young children · PCB $\cdot$ IL-8 $\cdot$ IL-22 · Allergy

\section{Introduction}

Allergic diseases, including atopic dermatitis (AD), food allergies, allergic rhinitis, and asthma, are the most common chronic diseases in developed countries and affect up to $20 \%$ of children in industrialized nations [1,2]. According to a previous report, asthma is particularly associated with developed countries [3]. The development of allergic disorders is attributed to a series of complex interactions between individuals' genetic backgrounds and their immune and psychoneurotic responses to environmental factors [4]. Detailed analyses of the family histories of atopic patients have shown that $50-75 \%$ of patients harbor family histories of atopic disease [2]. In addition, the concordance rates of asthma, $\mathrm{AD}$, and bronchial hyperresponsiveness were found to be higher among monozygotic twin pairs than among dizygotic twin pairs [5]. However, the mechanisms involved in the inheritance of allergic disease are not fully understood. In our previous study, we examined the concordance rates of positive responses to food and indoor allergens between siblings with $\mathrm{AD}$, and the factors associated with the subjects' responses to such allergens [6]. In the latter study, only allergen-specific positive responses to oil seeds, i.e., peanuts, sesame seeds, and soybeans, exhibited concordance between siblings. In addition, there was no significant correlation in the responses induced by egg during CAP radioallergosorbent tests (CAP-RAST) between sibling pairs although the frequency of positive CAP-RAST results was highest for egg 
[6]. Furthermore, Howell et al. [7] detected a specific human leukocyte antigen class II polymorphism among patients with peanut allergies. Together, these findings suggest that genetic factors might be involved in the development of some food allergies such as oil seed allergies. However, recent studies have produced contradictory results [8].

It is considered that age and individual and environmental factors affect allergy development. Among the various possible causes of allergic symptoms, the early exposure of developing infants to air pollutants and the presence of persistent chemical pollutants such as pesticides have been cited most frequently [9]. However, it has been very difficult to obtain epidemiological proof of direct associations between exposure to low levels of environmental pollutants and clearly defined adverse health effects in children. The main epidemiological methodologies used to study the health effects of environmental pollutants involve finding correlations between the levels of pollutant residues present in air, water, food, or certain compartments of the body and the incidences of specific allergic diseases $[10,11]$. While the above approach has provided a great deal of evidence regarding the deleterious effects of environmental pollution such as those associated with accidental or occupational contamination by lead, arsenic, or mercury (i.e., the effects of pollutants from point sources) $[12,13]$, it has not proved as effective in studies investigating the effects of low concentrations of persistent organic pollutants such as polychlorinated biphenyls (PCBs) and dioxins (i.e., the effects of pollutants from nonpoint sources), which are frequently found among ordinary citizens, although some studies have suggested that exposure to the latter pollutants is associated with the risk of particular diseases [14, 15]. This is because the health effects of environmental pollutants represent the end result of complex interactions between toxic chemicals and the physiological condition of vulnerable tissues, which is influenced by both the genetic background of the affected individual and their lifestyle, e.g., their diet and home environment $[16,17]$.

We hypothesized that a hyperallergic predisposition might be one of the key physiological conditions that make children more susceptible to allergic disorders after being exposed to environmental pollutants. To test the above hypothesis, we made it our primary objective to identify and establish health-related biomarkers that could be used to assess the adverse health effects of environmental pollutants, especially PCBs, in children $[18,19]$. In this review, we mainly summarize the findings of our two previous studies, which involved the same study populations. In the first study, which examined the relationship between asthma and PCBs, the candidate biomarkers were interleukin (IL)-8 and cyclooxygenase (COX)-2 [18]. In the second study, which investigated the relationship between food-specific immunoglobulin $\mathrm{E}(\mathrm{IgE})$ reactions and $\mathrm{PCBs}$, the candidate biomarkers were IL-6; IL-8; IL-10; IL-17; IL-22; COX-2; cytochrome $\mathrm{P} 450$, family 1 , subfamily A, polypeptide 1 (CYP1A1); forkhead box P3 (Foxp3); suppressor of cytokine signaling 3 (SOCS3); and RelB [19]. In the last section, we briefly introduce our latest study, which tested the prediction that in utero PCB exposure adversely affects placental morphology, potentially leading to placental insufficiency followed by fetal growth restriction [intrauterine growth restriction (IUGR)] and the onset of childhood allergies [20].

\section{Experimental designs to find new biomarkers}

\section{Subjects}

The subjects were recruited at a dermatological and allergy clinic at Kumamoto city (Kyusyu, southern Japan) from January 2009 to February 2010. We subjected 203 preschool children to a questionnaire (age $<4$ years old) after their parents or guardians had agreed to their participation. Finally, asthmatic subjects $(N=15)$ and non-matched, non-asthmatic subjects $(N=15)$ were selected. Non-fasting venous blood was collected on the day of the interview from children who had not suffered any diseases during the month before the interview.

\section{Questionnaire}

The questionnaire used at the interview included questions about the number of siblings, the duration of breast feeding, the smoking habits of the subject's parents, the distance from the subject's home to the nearest large road (i.e., $<50 \mathrm{~m}$ or $\geq 50 \mathrm{~m}$ ), the subject's history of allergies, and the subject's parents' history of allergies. When the subjects' parents were classified according to their smoking habits, those who had never smoked near to their children were counted as non-smokers.

\section{PCB assessment}

The serum samples that we collected for the PCB measurements were shipped to Environmental Idea Research Laboratory (Kankyo-Sozo), Inc., which analyzed individual PCB congener levels using high-resolution gas chromatography/high-resolution mass spectrometry. The limit of detection of each PCB congener was as follows $(\mathrm{pg} / \mathrm{g}$ wet): \#74 + \#61: 0.09, \#99: 0.1, \#118: 0.2, \#138: 0.3, \#146: 0.4, \#153: 0.4, \#156: 0.2, \#163 + \#164: 0.3, \#170: 0.6, \#177: 0.4, \#178: 0.5, \#180 + \#193: 0.4, \#183: 0.5, $\# 187+\# 182: 0.5$, \#194: 0.4, \#199 + \#198: 0.5. If a particular PCB isomer was not detected, its concentration was defined as 0 when calculating the total PCB concentration. 
Candidate biomarkers and quantitative real-time PCR (qRT-PCR)

The following candidate biomarkers were examined in this study: IL-6, IL-8, IL-10, IL-17, IL-22, COX-2, CYP1A1, Foxp3, SOCS3, and RelB. The mRNA expression level of each gene was analyzed by subjecting the children's blood samples. Total RNA was isolated from children's whole blood using QIAamp RNA Blood Mini kit (Qiagen, Hilden, Germany). RNA was reverse transcribed into cDNA using QuantiTect Reverse Transcription (Qiagen). The basic quantitative reverse transcription-polymerase chain reaction (qRTPCR) protocol was as described in our previous paper [21].

\section{Allergen-specific IgE assays}

Serum samples were collected from the patients at the clinic, and CAP-RAST were used to assess the subjects' antigen-specific IgE levels at FALCO Biosystems Ltd., Japan. An antigen-specific IgE concentration of $\geq 0.35 \mathrm{UA} /$ $\mathrm{ml}$ was considered to indicate sensitization [22, 23] so subjects that exhibited antigen-specific IgE concentrations of $\geq 0.35$ and $<0.35 \mathrm{UA} / \mathrm{ml}$ were categorized as positive and negative, respectively.

\section{Statistical methods}

In our first study, the associations between serum $\mathrm{PCB}$ levels and the mRNA expression level of IL-8 or COX-2 were analyzed using univariate regression models in which IL-8 or COX-2 was employed as a dependent variable after natural logarithmic conversion. We divided the subjects into 3 groups depending on the levels of each PCB congener (i.e., into low, medium, and high exposure groups), and each sub-group consisted of approximately one-third of the subjects (i.e., tertiles). Trend tests for each PCB congener were conducted using univariate regression models and tertile scores (low $=1$, medium $=2$, and high $=3$ ).

In our second study, the Mann-Whitney $U$ test was used to compare the mRNA levels of the food-specific IgEnegative and -positive groups.

All analyses were performed using STATA version 10 (Stata Corporation, USA), and all presented $P$ values are two-sided.

\section{Comprehensive study results}

\section{Subjects' characteristics}

The mean age (SE) of our study subjects $(N=30)$ was 22.7 (1.8) months old, and the SE of their mothers was 30.5 (0.7) years old. A clinical history of house dust mite-specific allergic IgE reactions was more common among the
Table 1 Total serum levels of PCB according to the presence of allergic conditions

\begin{tabular}{|c|c|c|}
\hline & \multicolumn{2}{|c|}{ All subjects, total PCBs } \\
\hline & Median $(95 \% \mathrm{CI})$ & $P$ value \\
\hline \multicolumn{3}{|l|}{ Asthma } \\
\hline Non-asthmatic children & $312(265,765)$ & 0.120 \\
\hline Asthmatic children & $620(429,866)$ & \\
\hline \multicolumn{3}{|l|}{ Egg-specific IgE } \\
\hline Negative & $326(213,817)$ & 0.189 \\
\hline Positive & $597(427,840)$ & \\
\hline \multicolumn{3}{|l|}{ Milk-specific IgE } \\
\hline Negative & $435(291,592)$ & 0.028 \\
\hline Positive & $836(492,1155)$ & \\
\hline \multicolumn{3}{|l|}{ Wheat-specific IgE } \\
\hline Negative & $435(291,592)$ & 0.091 \\
\hline Positive & $762(448,973)$ & \\
\hline \multicolumn{3}{|c|}{ House dust mite-specific $\operatorname{IgE}^{\mathrm{a}}$} \\
\hline Negative & $491(294,955)$ & 0.807 \\
\hline Positive & $567(246,873)$ & \\
\hline
\end{tabular}

asthmatic children than among the controls $(P=0.021)$ (data not shown).

Serum levels of total PCBs among allergic conditions

The children with allergic conditions displayed higher PCB concentrations than the non-allergic children. In addition, the children's serum PCB levels differed among the various allergic conditions. In particular, it was found that those who exhibited positive allergic reactions to milkspecific IgE demonstrated significantly elevated serum levels of total PCBs (Table 1).

Study 1: a study of the relationship between asthma and PCB congeners

The results of our examination of the associations between the levels of individual and total PCBs and the mRNA expression level of IL-8 are summarized in Table 2 (note that only individual PCB congeners that exhibited significant correlations with IL-8 expression are shown). Interestingly, IL-8 only exhibited significant correlations with the serum levels of individual congeners (PCB \#163 + \#164, \#170, \#177, \#178 and \#180 + \#193) among the asthmatic subjects. Conversely, COX-2 only demonstrated correlations with the serum levels of individual PCB congeners among the nonasthmatic subjects (data not shown).

Upon further analysis, it was found that in most cases, the effects of individual PCB congeners on IL- 8 expression 
Table 2 Concentration-dependent associations between the concentrations of individual and total PCB and the mRNA expression level of IL-8 among all subjects, the non-asthmatic (control) subjects and the asthmatic subjects [18]

\begin{tabular}{|c|c|c|c|}
\hline & \multicolumn{3}{|l|}{ IL-8 } \\
\hline & Coefficient & SE & $P$ for trend* \\
\hline \multicolumn{4}{|c|}{ PCB \#163 + \#164 } \\
\hline All & 0.164 & 0.070 & 0.021 \\
\hline Control & 0.064 & 0.097 & 0.480 \\
\hline Asthma & 0.270 & 0.115 & 0.022 \\
\hline \multicolumn{4}{|l|}{ PCB \#170 } \\
\hline All & 0.153 & 0.071 & 0.032 \\
\hline Control & 0.068 & 0.099 & 0.465 \\
\hline Asthma & 0.217 & 0.109 & 0.046 \\
\hline \multicolumn{4}{|l|}{ PCB \#177 } \\
\hline All & 0.164 & 0.070 & 0.021 \\
\hline Control & 0.064 & 0.097 & 0.480 \\
\hline Asthma & 0.270 & 0.115 & 0.022 \\
\hline \multicolumn{4}{|l|}{ PCB \#178 } \\
\hline All & 0.164 & 0.070 & 0.021 \\
\hline Control & 0.064 & 0.097 & 0.480 \\
\hline Asthma & 0.270 & 0.115 & 0.022 \\
\hline \multicolumn{4}{|c|}{ PCB \#180 + \#193 } \\
\hline All & 0.154 & 0.071 & 0.032 \\
\hline Control & 0.068 & 0.099 & 0.465 \\
\hline Asthma & 0.217 & 0.109 & 0.046 \\
\hline \multicolumn{4}{|c|}{ Total PCBs } \\
\hline All & 0.133 & 0.073 & 0.065 \\
\hline Control & 0.064 & 0.097 & 0.480 \\
\hline Asthma & 0.180 & 0.128 & 0.145 \\
\hline
\end{tabular}

In each correlation study, PCB levels were first stratified by tertile and then assessed using univariate regression analysis

Coefficient: regression coefficient

$S E$ standard error

* $P$ for trend was obtained using a univariate regression model

were most pronounced among the highest tertile, as shown for \#163 + 164 in Fig. 1.

Study 2: a study of the relationship between foodspecific IgE and PCB congeners

\section{Relationships between the expression levels} of the candidate biomarkers and the distance from the child's home to the nearest large road in two sub-groups based on food-specific IgE status

In an initial effort to identify biomarkers that could be used to correctly determine the influence of environmental factors on the health of the study subjects, we assessed the associations between living near to major roads and the mRNA expression levels of 10 potential biomarkers. Among them, the mRNA expression levels of IL-22 and CYP1A1 exhibited significant correlations with the proximity of the child's home to major highways (Table 3). When the subjects were divided into two sub-groups based on whether they exhibited positive or negative IgE reactions to egg, milk, or wheat, as evaluated based on their serum levels of specific IgE, IL-22 expression was found to be significantly correlated with the proximity of the child's home to major highways among the IgE-positive children, but not among the IgE-negative sub-group, suggesting that the former sub-group represents a susceptible sub-population that is more likely to be adversely affected by the environmental risk factors associated with major highways.

Relationships between the candidate biomarkers and each food-specific IgE reaction

To identify the specific type of hyperallergic predisposition that significantly influences the expression of each biomarker, we divided the 30 study subjects into two subgroups according to whether they showed positive or negative IgE reactions to egg, milk, or wheat, and assessed the associations between each $\operatorname{IgE}$ reaction and the mRNA expression levels of the 10 potential biomarkers to gain a perspective on the relative importance of IL-22 as a biomarker. IL-22 was the only marker that was consistently significantly associated with positive $\operatorname{IgE}$ reactions. Namely, IL-22 was found to be significantly associated with egg- or milk-specific, but not wheat-specific, positive IgE reactions in children (data not shown).

Relationships between egg-or milk-specific IgE reactions and IL-22 expression according to PCB tertile

Since air pollutants include PCBs [24, 25] and subjects that lived close to major highways exhibited high serum PCB levels (pg/g-wet) $[\geq 50 \mathrm{~m}$; median $=480,95 \%$ confidence interval (CI): 291, 742, $<50 \mathrm{~m} ;$ median $=548$, $95 \%$ CI: 312, 1018; $p=0.512$ ] (data not shown). When the association between IL-22 expression and the total serum level of PCB congeners was assessed among all children who showed egg- or milk-specific IgE reactions, the only significant difference was detected in the milkspecific IgE group with high serum PCB levels (Table 4).

The frequency of correlations between IL-22 and individual congeners (i.e., PCB \#61 + 71,\#99, \#118, \#138, \#146, \#158, \#156, \#163 + 164, \#170, \#177, \#178, $\# 180+193, \# 183, \# 182+187, \# 194$, and \#198 + 199) was higher among the subjects who showed positive allergic IgE reactions to milk (data not shown). 


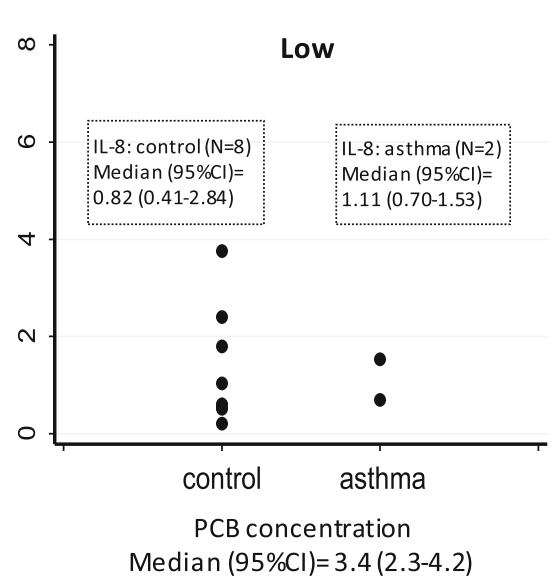

Fig. 1 Differences in the expression level of IL- 8 mRNA between non-asthmatic (control) and asthmatic children in three different subgroups (tertiles) that exhibited low, medium, or high serum levels of

\section{Who is ultra-sensitive to IL-22 overexpression?}

To examine whether other environmental pollutants apart from PCBs make certain individuals overexpress IL-22, we assessed whether asthmatic children are hyperresponsive to other environmental stress factors. For this purpose, we divided the subjects into four sub-groups according to their asthmatic condition and IgE status (Fig. 2). As a result, we found that when the asthmatic subjects who exhibited positive $\operatorname{IgE}$ reactions were directly compared with the non-asthmatic subjects who displayed negative IgE reactions IL-22 expression was significantly higher in the asthmatic children that exhibited positive IgE reactions to milk or egg. At the same time, it was noticed that in all cases the expression level of IL-22, which is closely associated with lung inflammation, was always higher within each IgE-positive sub-group than in the corresponding IgE-negative group, although the differences were not always statistically significant. This IL-22enhancing effect of $\operatorname{IgE}$ was clearly exacerbated among the asthmatic children.

\section{Discussion}

The main objective of this study was to identify appropriate biomarkers for assessing the associations between adverse health effects and exposure to low levels of pollutants, such as PCBs. In study 1 , we used asthma as an adverse health effect. The serum concentrations of several PCB congeners were found to be significantly correlated with the mRNA expression level of IL-8 among asthmatic children. In study 2 , we used specific IgE reactions to food as an adverse health effect and showed that IL-22 expression is

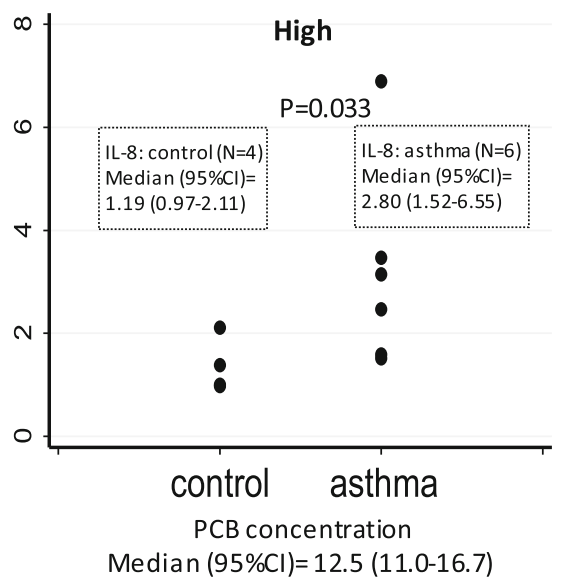

PCB congener $\# 163+164$ [18]. $P$ values were obtained using the Mann-Whitney $U$ test

particularly useful for detecting the effects of air pollutants, especially PCBs.

Study 1: IL-8, a chemokine associated with inflammation, has been reported to be linked to childhood allergies, particularly those involving inflammation of the airways, which can result in wheezing or asthma [26-28]. As for the use of IL- 8 as a biomarker, IL- 8 has already been suggested to be a marker of asthma and/or other inflammatory lung conditions such as chronic obstructive pulmonary disease by a number of other scientists [29, 30]. Nevertheless, despite the wealth of information about the relationship between IL-8 and asthma, no one has investigated whether IL-8 is a useful biomarker for examining the link between PCB exposure and childhood asthma. Study 2: as IL-22 has often been demonstrated to be associated with allergic diseases [17, 22, 31-33], it is not surprising that we found it to be associated with egg- and milk-specific IgE reactions in this study. However, none of the previous studies addressed whether IL-22 expression is associated with PCB exposure. The causative mechanisms of asthma and food allergies differ. Asthma is related to type $2 \mathrm{~T}$ helper cellinduced reversible airway obstruction and hyper responsiveness [34]. On the other hand, food allergies are caused by disruption of the intestinal barrier [35]. Therefore, it is possible that the effects of environmental pollutants on these conditions are mediated by different cytokines.

Our use of a tertile-based approach helped us to detect statistically significant correlations in the present study; i.e., it demonstrated that the high PCB exposure groups tended to display the strongest correlations. It must be pointed out that in addition to PCB, environmental pollution also includes polycyclic aromatic hydrocarbons $(\mathrm{PAH})$, nitro-PAH, 1-nitropyrene, etc. [24, 25]. In other words, PCBs might not be the only pollutants affecting IL- 


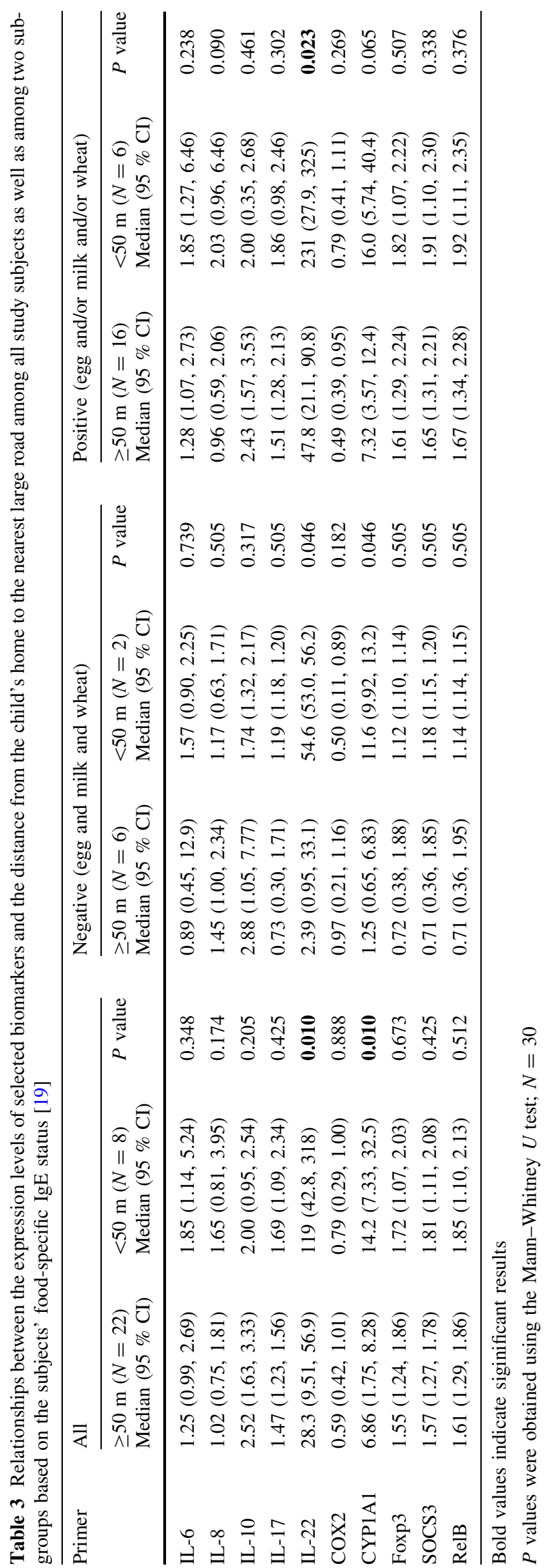

Table 4 Association between milk-specific IgE reactions and IL-22 expression as analyzed by total PCB tertile [19]

\begin{tabular}{|c|c|c|c|c|c|}
\hline $\begin{array}{l}\text { Total PCB } \\
\text { tertile }\end{array}$ & $\begin{array}{l}\text { Negative } \\
(N)\end{array}$ & $\begin{array}{l}\text { Median } \\
(95 \% \mathrm{CI})\end{array}$ & $\begin{array}{l}\text { Positive } \\
(N)\end{array}$ & $\begin{array}{l}\text { Median } \\
(95 \% \mathrm{CI})\end{array}$ & $P$ value \\
\hline Low & 9 & $\begin{array}{c}17.5(3.61 \\
136)\end{array}$ & 1 & $\begin{array}{c}78.8(78.8 \\
78.8)\end{array}$ & 0.602 \\
\hline Medium & 8 & $\begin{array}{l}54.6(15.2, \\
278)\end{array}$ & 2 & $\begin{array}{c}62.7(21.6 \\
104)\end{array}$ & 1.000 \\
\hline High & 5 & $\begin{array}{l}24.2(1.00 \\
61.7)\end{array}$ & 5 & $\begin{array}{c}154(42.1 \\
326)\end{array}$ & 0.028 \\
\hline
\end{tabular}

8 and IL-22 mRNA expressions. However, it is important to note that significant associations between IL-8 or IL-22 mRNA expression and the serum levels of PCBs were only found among children with asthma or positive IgE reactions to milk (i.e., a food allergy), respectively.

It is necessary to point out some limitations in these studies. First, our study subjects were young children and it was difficult in several cases to collect the standard blood volume necessary to analyze serum biomarkers by ELISA. Second, it will be beneficial to include TEQ/TEF-type assessments to be clear which type of PCB congeners are associated with childhood conditions, such as allergies in the future. In addition, further efforts are needed to search for biomarkers that would provide us with the mechanistic insights required to understand the associations between exposure to PCBs and other environmental pollutants and the pathogeneses of childhood asthma and food allergies.

\section{Our latest study and future research topics: the association between PCBs and placental morphology}

IUGR is defined as the insufficient expression of genetic fetal growth potential. Numerous reports have described PCB-dependent adverse effects on human fetal growth, including an increased risk of IUGR, changes in endocrine function and hormone metabolism, and immunosuppressive and neurological deficits [36, 37]. In our study, we did not detect a significant relationship between low birth weight and PCB exposure (data not shown). However, some previous studies have suggested that low birth weight is associated with childhood allergies [38, 39]. Therefore, we will attempt to clarify the relationship between childhood allergies, birth weight, and in utero PCB exposure. As a first step, we have attempted to test the prediction that in utero PCB exposure adversely effects placental morphology, potentially leading to placental insufficiency, which can result in IUGR. To do this, we measured the serum 

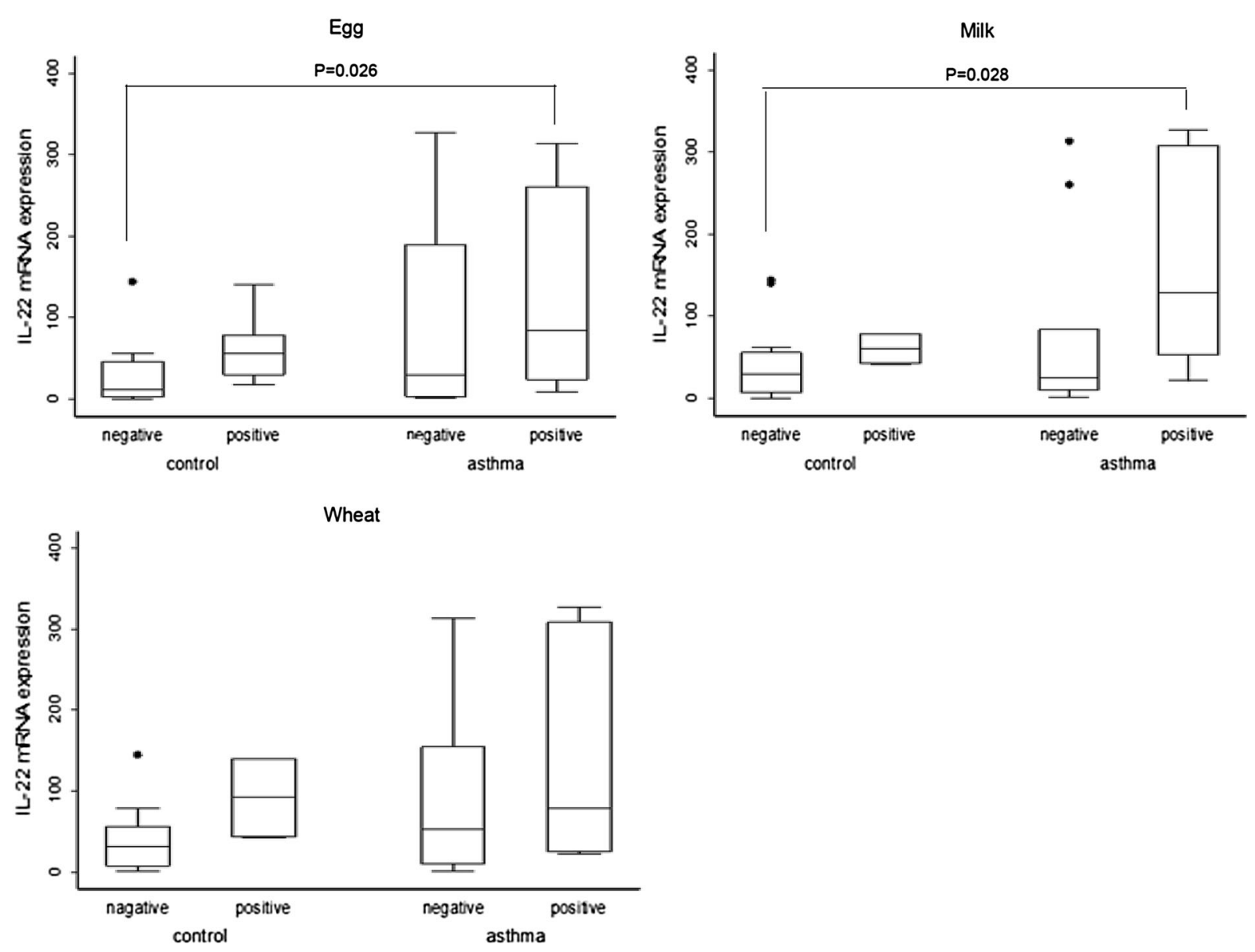

Fig. 2 Associations between IL-22 expression and allergen-specific IgE reactions [19]. The numbers of subjects in each category were as follows: egg There were 8 non-asthmatic (control) egg-specific IgEnegative children, 7 control egg-specific IgE-positive children, 4 asthmatic egg-specific IgE-negative children, and 11 asthmatic eggspecific IgE-positive children. Milk There were 13 control milkspecific IgE-negative children, 2 control milk-specific IgE-positive

children, 9 asthmatic milk-specific IgE-negative children, and 6 asthmatic milk-specific IgE-positive children. Wheat There were 13 control wheat-specific IgE-negative children, 2 control wheat-specific IgE-positive children, 9 asthmatic wheat-specific IgE-negative children, and 6 asthmatic wheat-specific IgE-positive children. $P$ values were obtained by Mann-Whitney $U$ test

Table 5 Relationships between the total maternal/cord blood PCB concentration and ST volume or the placental concentration of PIGF or SFlt-1 [20]

\begin{tabular}{|c|c|c|c|c|c|c|c|c|c|}
\hline & \multicolumn{3}{|l|}{$\mathrm{ST}^{\mathrm{b}}$} & \multicolumn{3}{|l|}{$\mathrm{PlGF}^{\mathrm{a}, \mathrm{b}}$} & \multicolumn{3}{|l|}{ sFlt- $1^{a, b}$} \\
\hline & Coefficient & SE & $P$ value & Coefficient & SE & $P$ value & Coefficient & SE & $P$ value \\
\hline Total PCB (pg/g-fat) in maternal blood & -1.77 & 0.93 & 0.076 & 2.35 & 0.90 & 0.019 & 0.10 & 1.31 & 0.943 \\
\hline Total PCB (pg/g-fat) in cord blood & -1.02 & 1.61 & 0.534 & 3.89 & 0.95 & 0.001 & -1.03 & 2.01 & 0.615 \\
\hline
\end{tabular}

$P$ values were obtained using multivariate regression models

Placental weight, the PIGF concentration, and the sFlt concentration were included as covariates

Coefficient: regression coefficient

$S E$ standard error

${ }^{\text {a }} N=21$

b $z$ score transformation was performed

levels of 10 PCB homologs in maternal and fetal blood samples collected from a small cohort of normotensive pregnant women $(N=22)$ who participated in the Japan environment and children's study pilot study using gas chromatography mass spectrometry [40]. The subjects' serum PCB levels were compared with their placental 
concentrations of angiogenesis-associated proteins such as placental growth factor (PIGF) and soluble fms-like tyrosine kinase 1 (sFlt-1), which were determined by ELISA, and the total estimated syncytiotrophoblast (ST) volume. As a result, the extent of environmental PCB exposure (based on blood PCB levels) was found to be negatively associated with the ST volume. In addition, positive relationships were detected between the maternal/fetal blood levels of PCBs and the placental PIGF protein concentration, while no such relationship was detected for the placental sFlt-1 concentration (Table 5). These results demonstrate that the human placenta, including ST, is a target of PCB toxicity, and that current environmental PCB exposure levels are a risk to reproductive health.

Children's blood PCB concentrations are affected by their lifestyle. At present, the association between exposure to low levels of PCBs and placental function is poorly understood. We will continue to study these associations and the effects of PCB exposure on childhood allergies.

\section{Conclusion}

In conclusion, we showed that IL-8 and IL-22 mRNA expressions are particularly useful for detecting the effects of environmental pollutants, especially PCB congeners, in vulnerable children with asthma or those who exhibit positive IgE responses to milk or egg.

Acknowledgments My deepest appreciation goes to Prof. Fumio Matsumura. I had great support and encouragement from him until he passed away. Without his guidance and persistent help, these studies would not have been possible.

I would like to express heartfelt thanks to Prof. Suminori Akiba, Prof. Takahiko Katoh, and Prof. Toshihiro Kawamoto, whose comments and suggestions were invaluable throughout the course of my study. I am also in debt to Dr. Chihaya Koriyama and Dr. Megumi Yamamoto, who gave me invaluable comments and warm encouragement.

Conflict of interest The authors declare that they have no conflicts of interest.

\section{References}

1. Strachan D, Sibbald B, Weiland S, Ait-Khaled N, Anabwani G, Anderson HR, et al. Worldwide variations in prevalence of symptoms of allergic rhinoconjunctivitis in children: the international study of asthma and allergies in childhood (ISAAC). Pediatr Allergy Immunol. 1997;8:161-76.

2. Korol D, Kaczmarski M. Positive family history of allergy in children with hypersensitivity to cow's milk. Med Sci Monit. 2001;7:966-70.

3. Beasley R, Crane J, Lai CK, Pearce N. Prevalence and etiology of asthma. J Allergy Clin Immunol. 2000;105:S466-72.

4. Hudson TJ. Skin barrier function and allergic risk. Nat Genet. 2006;38:399-400.
5. Clarke JR, Jenkins MA, Hopper JL, Carlin JB, Mayne C, Clayton DG, et al. Evidence for genetic associations between asthma, atopy, and bronchial hyperresponsiveness: a study of 8- to 18-yrold twins. Am J Respir Crit Care Med. 2000;162:2188-93.

6. Tsuji M, Koriyama C, Inaba Y, Akiba S. Concordance of CAP-RAST responses for food and indoor allergens between sibling pairs with atopic dermatitis. Med J Kagoshima. 2008;59:37-47.

7. Howell WM, Turner SJ, Hourihane JO, Dean TP, Warner JO. HLA class II DRB1, DQB1 and DPB1 genotypic associations with peanut allergy: evidence from a family-based and casecontrol study. Clin Exp Allergy. 1998;28:156-62.

8. Shreffler WG, Charlop-Powers Z, Sicherer SH. Lack of association of HLA class II alleles with peanut allergy. Ann Allergy Asthma Immunol. 2006;96:865-9.

9. Salam MT, Li YF, Langholz B, Gilliland FD. Early-life environmental risk factors for asthma: findings from the children's health study. Environ Health Perspect. 2004;112:760-5.

10. Tashakkor AY, Chow KS, Carlsten C. Modification by antioxidant supplementation of changes in human lung function associated with air pollutant exposure: a systematic review. BMC Public Health. 2011;11:532.

11. Mann JK, Balmes JR, Bruckner TA, Mortimer KM, Margolis HG, Pratt B, et al. Short-term effects of air pollution on wheeze in asthmatic children in Fresno, California. Environ Health Perspect. 2010;118:1497-502.

12. Jarup L. Hazards of heavy metal contamination. Br Med Bull. 2003;68:167-82.

13. Sakamoto M, Feng X, Li P, Qiu G, Jiang H, Yoshida M, et al. High exposure of Chinese mercury mine workers to elemental mercury vapor and increased methylmercury levels in their hair. Environ Health Prev Med. 2007;12:66-70.

14. Przyrembel H, Heinrich-Hirsch B, Vieth B. Exposition to and health effects of residues in human milk. Adv Exp Med Biol. 2000;478:307-25.

15. Gallagher RP, Macarthur AC, Lee TK, Weber JP, Leblanc A, Mark EJ, et al. Plasma levels of polychlorinated biphenyls and risk of cutaneous malignant melanoma: a preliminary study. Int $\mathbf{J}$ Cancer. 2011;128:1872-80.

16. Dutta SK, Mitra PS, Ghosh S, Zang S, Sonneborn D, HertzPicciotto I, et al. Differential gene expression and a functional analysis of PCB-exposed children: understanding disease and disorder development. Environ Int. 2012;40:143-54.

17. Mitra PS, Ghosh S, Zang S, Sonneborn D, Hertz-Picciotto I, Trnovec $\mathrm{T}$, et al. Analysis of the toxicogenomic effects of exposure to persistent organic pollutants (POPs) in Slovakian girls: correlations between gene expression and disease risk. Environ Int. 2012;39:188-99.

18. Tsuji M, Vogel CF, Koriyama C, Akiba S, Katoh T, Kawamoto $\mathrm{T}$, et al. Association of serum levels of polychlorinated biphenyls with IL-8 mRNA expression in blood samples from asthmatic and non-asthmatic Japanese children. Chemosphere. 2012;87:1228-34.

19. Tsuji M, Kawamoto T, Koriyama C, Matsumura F. IL-22 mRNA expression in blood samples as a useful biomarker for assessing the adverse health effects of PCBs on allergic children. Int J Environ Res Public Health. 2012;9:4321-32.

20. Tsuji M, Aiko Y, Kawamoto T, Hachisuga T, Kooriyama C, Myoga M, et al. Polychlorinated biphenyls (PCBs) decrease the placental syncytiotrophoblast volume and increase placental growth factor (PIGF) in the placenta of normal pregnancy. Placenta. 2013;34:619-23.

21. Vogel CF, Sciullo E, Wong P, Kuzmicky P, Kado N, Matsumura F. Induction of proinflammatory cytokines and C-reactive protein in human macrophage cell line U937 exposed to air pollution particulates. Environ Health Perspect. 2005;113:1536-41. 
22. Commins SP, Satinover SM, Hosen J, Mozena J, Borish L, Lewis $\mathrm{BD}$, et al. Delayed anaphylaxis, angioedema, or urticaria after consumption of red meat in patients with IgE antibodies specific for galactose-alpha-1, 3-galactose. J Allergy Clin Immunol. 2009;123:426-33.

23. Kotaniemi-Syrjanen A, Reijonen TM, Romppanen J, Korhonen K, Savolainen K, Korppi M. Allergen-specific immunoglobulin E antibodies in wheezing infants: the risk for asthma in later childhood. Pediatrics. 2003;111:e255-61.

24. Wu J, Teng M, Gao L, Zheng M. Background air levels of polychlorinated biphenyls in China. Sci Total Environ. 2011;409:1818-23.

25. Andersson H, Piras E, Demma J, Hellman B, Brittebo E. Low levels of the air pollutant 1-nitropyrene induce DNA damage, increased levels of reactive oxygen species and endoplasmic reticulum stress in human endothelial cells. Toxicology. 2009;262:57-64.

26. Herberth G, Gubelt R, Roder S, Kramer U, Schins RP, Diez U, et al. Increase of inflammatory markers after indoor renovation activities: the LISA birth cohort study. Pediatr Allergy Immunol. 2009;20:563-70.

27. Silvestri M, Bontempelli M, Giacomelli M, Malerba M, Rossi GA, Di Stefano A, et al. High serum levels of tumour necrosis factor-alpha and interleukin-8 in severe asthma: markers of systemic inflammation? Clin Exp Allergy. 2006;36:1373-81.

28. Tadaki H, Arakawa H, Sugiyama M, Ozawa K, Mizuno T, Mochizuki $\mathrm{H}$, et al. Association of cord blood cytokine levels with wheezy infants in the first year of life. Pediatr Allergy Immunol. 2009;20:227-33.

29. Grob M, Schmid-Grendelmeier P, Joller-Jemelka HI, Ludwig E, Dubs RW, Grob PJ, et al. Altered intracellular expression of the chemokines MIP-1alpha, MIP-1beta and IL- 8 by peripheral blood $\mathrm{CD} 4+$ and $\mathrm{CD} 8+\mathrm{T}$ cells in mild allergic asthma. Allergy. 2003;58:239-45.

30. Shute JK, Vrugt B, Lindley IJ, Holgate ST, Bron A, Aalbers R, et al. Free and complexed interleukin- 8 in blood and bronchial mucosa in asthma. Am J Respir Crit Care Med. 1997;155:1877-83.
31. Farfariello V, Amantini C, Nabissi M, Morelli MB, Aperio C, Caprodossi S, et al. IL-22 mRNA in peripheral blood mononuclear cells from allergic rhinitic and asthmatic pediatric patients. Pediatr Allergy Immunol. 2011;22:419-23.

32. Zhu J, Cao Y, Li K, Wang Z, Zuo P, Xiong W, et al. Increased expression of aryl hydrocarbon receptor and interleukin 22 in patients with allergic asthma. Asian Pac J Allergy Immunol. 2011;29:266-72.

33. Martino DJ, Bosco A, McKenna KL, Hollams E, Mok D, Holt PG, et al. T-cell activation genes differentially expressed at birth in CD4+ T-cells from children who develop IgE food allergy. Allergy. 2012;67:191-200.

34. Djukanovic R, Roche WR, Wilson JW, Beasley CR, Twentyman OP, Howarth RH, et al. Mucosal inflammation in asthma. Am Rev Respir Dis. 1990;142:434-57.

35. Jeon MK, Klaus C, Kaemmerer E, Gassler N. Intestinal barrier: molecular pathways and modifiers. World J Gastrointest Pathophysiol. 2013;4:94-9.

36. Fein GG, Jacobson JL, Jacobson SW, Schwartz PM, Dowler JK. Prenatal exposure to polychlorinated biphenyls: effects on birth size and gestational age. J Pediatr. 1984;105:315-20.

37. Halldorsson TI, Thorsdottir I, Meltzer HM, Nielsen F, Olsen SF. Linking exposure to polychlorinated biphenyls with fatty fish consumption and reduced fetal growth among Danish pregnant women: a cause for concern? Am J Epidemiol. 2008;168:958-65.

38. Costa LC, Rezende ER, Segundo GRS. Growth parameters impairment in patients with food allergies. J Allergy (Cairo). 2014;2014. Article ID 980735. doi:10.1155/2014/980735

39. Liu X, Olsen J, Agerbo E, Yuan W, Cnattingius S, Gissler M, et al. Birth weight, gestational age, fetal growth and childhood asthma hospitalization. Allergy Asthma Clin Immunol. 2014;10:13.

40. Kawamoto T, Nitta H, Murata K, Toda E, Tsukamoto N, Hasegawa $\mathrm{M}$, et al. Rationale and study design of the Japan environment and children's study (JECS). BMC Public Health. 2014;14:25. 